\title{
Repercussões do Programa Bolsa Família no município de Araraquara, SP: um olhar sobre a segurança alimentar e nutricional dos beneficiários
}

Repercussions of the Bolsa Familia Program in the city of Araraquara, SP: a look at food security and nutritional status of beneficiaries

Répercussions du Programme Bolsa Familia dans la ville de Araraquara, SP: un regard sur la sécurité alimentaire et l'état nutritionnel des bénéficiaires

Repercusiones del Programa Bolsa Familia en la ciudad de Araraquara, SP: una mirada a la seguridad alimentaria y el estado nutricional de los beneficiarios

\author{
Daiane Roncato Cardozo Traldi* \\ Luiz Manoel de Moraes Camargo Almeida** \\ Vera Lúcia Silveira Botta Ferrante***
}

Recebido em 22/4/2011; revisado e aprovado em 13/7/2011; aceito em 20/11/2011

\begin{abstract}
Resumo : Este trabalho discorre sobre as repercussões do Programa Bolsa Família em elementos da temática da segurança alimentar, tomando como parâmetro de análise beneficiários do município de Araraquara, SP. A partir da aplicação de formulários semiestruturados com os beneficiários e das observações de campo, o diagnóstico foi realizado tendo como perspectiva teórica a avaliação de políticas públicas.

Palavras-chave: Políticas públicas. Programa Bolsa Família. Segurança Alimentar e Nutricional.

Abstract : This study discusses the repercussions of the Bolsa Familia in elements of the theme of food security, taking as parameters of analysis the beneficiaries of the city of Araraquara, SP. From the application form semistructured with beneficiaries and field observations, the diagnosis was performed in an attempt to theoretical evaluation of public policies.

Key words: Public policies. Bolsa Familia Program. Food and Nutrition Security.

Résumé: Cette étude évalue les implications de la Bolsa Familia dans les éléments du thème de la sécurité alimentaire, en prenant comme paramètres des bénéficiaires de la ville de Araraquara, SP. Des formulaires de demande de semi-structurés avec les bénéficiaires et les observations de terrain, le diagnostic a été réalisée dans le but de l'évaluation théorique des politiques publiques.

Mots-clés: Politiques Publiques. Bolsa Familia. La sécurité alimentaire et la nutrition.

Resumen: Este estudio analiza las repercusiones del Bolsa Familia en los elementos del tema de la seguridad alimentaria, tomando como parámetros de análisis de los beneficiarios de la ciudad de Araraquara, SP. De los formularios de solicitud semiestructurados con los beneficiarios y las observaciones de campo, el diagnóstico se realizó en un intento de evaluación teórica de las políticas públicas.

Palabras clave: Políticas Públicas. Programa Bolsa Familia. Seguridad Alimentaria y Nutricional.
\end{abstract}

\section{Introdução}

As questões ligadas à pobreza, à fome, à desigualdade social, bem como o desafio da construção de uma sociedade mais justa e igualitária, como diz Mesquita (2007, p. 13): “ocupam as mentes (e corações) de pesquisadores e gestores públicos em vista dos elevados índices de iniquidades sociais que vêm se impondo em quase todo o mundo", principalmente em países com altas taxas de desigualdade como o Brasil.

\footnotetext{
* Administradora Pública pela Universidade Estadual de São Paulo (UNESP) de Araraquara. Bolsista pelo Programa de Suporte à Pós-Graduação de Instituições de Ensino Particulares (PROSUP) da Coordenação de Aperfeiçoamento de Pessoal de Nível Superior (CAPES) do Programa de Mestrado em Desenvolvimento Regional e Meio Ambiente do Centro Universitário de Araraquara (UNIARA), na linha de pesquisa em Políticas Públicas e Desenvolvimento. E-mail: daianecardozo@msn.com

${ }^{* *}$ Doutor em Políticas Públicas pela Faculdade de Engenharia Agrícola (FEAGRI) da Universidade Estadual de Campinas (UNICAMP). Pesquisador do Programa de Mestrado em Desenvolvimento Regional e Meio Ambiente do Centro Universitário de Araraquara (UNIARA). Professor Adjunto nível 1 da Faculdade de Agronomia e Engenharia de Alimentos da Universidade Federal de Goiás (UFG) na área de Políticas de Desenvolvimento e Sociologia Rural. E-mail: manoel77@yahoo.com.br

*** Livre-docente em Sociologia pela Universidade Estadual de São Paulo (UNESP) de Araraquara. Coordenadora do Programa de Mestrado em Desenvolvimento Regional e Meio Ambiente do Centro Universitário de Araraquara (UNIARA). E-mail: vbotta@uniara.com.br
} 
Nesse contexto, insere-se a abordagem das políticas públicas voltadas para a assistência social, especialmente as que visam ao combate à fome e à pobreza, promoção da saúde e da Segurança Alimentar e Nutricional $(\mathrm{SAN})^{1}$ e inclusão de pessoas em situação de risco e vulnerabilidade social.

A fim de tentar minimizar e/ou erradicar esses problemas, o Governo Federal brasileiro optou por investir em políticas públicas compensatórias ou nos chamados programas de Transferência Condicionada de Renda (TCR) ${ }^{2}$, que acabam substituindo ou complementando outros tipos de intervenções (BURLANDY, 2007). Para Santana (2007, p. 3), os programas de TCR surgiram como uma alternativa para combater a pobreza, pois "eles foram concebidos segundo a ideia de que o beneficiário tem a autonomia para definir como melhor utilizar o benefício por saber quais são suas necessidades mais urgentes".

Atualmente, o principal programa de TCR é o Programa Bolsa Família (PBF) ${ }^{3}$, criado em 2003 e que beneficia hoje mais de 12 milhões de famílias em situação de pobreza (com renda mensal por pessoa de $\mathrm{R} \$ 70,00$ a $\mathrm{R} \$ 140,00$ ) e extrema pobreza (com renda mensal por pessoa de até $\mathrm{R} \$ 70,00)$ em todos os municípios brasileiros, visando combater a miséria e a exclusão social e promover a emancipação das famílias mais pobres do nosso país (BRASIL, 2010).

Sabe-se que os maiores problemas na dimensão dessas políticas públicas são a eficiência, a eficácia e a sua continuidade, o que deixa aberto o caminho dessas iniciativas, isto é, se elas poderão representar casos concretos de políticas públicas, se são apenas progra-

\footnotetext{
${ }^{1}$ O Ministério do Desenvolvimento Social e Combate à Fome (MDS) (BRASIL, 2010), por intermédio da Secretaria Nacional de Segurança Alimentar e Nutricional (SESAN) é o responsável pelo desenvolvimento de políticas de SAN no Brasil que estão ligadas ao conjunto de estratégias do Programa Fome Zero (PFZ).

${ }^{2}$ Os programas TCR integram políticas de proteção social e combate à pobreza em diferentes países do mundo, inclusive no Brasil e destinam-se às famílias que vivem em contextos adversos (BURLANDY, 2007).

${ }^{3}$ O Bolsa Família é a unificação, racionalização e ampliação dos quatro programas sociais já existentes (Bolsa Escola, Bolsa Alimentação, Cartão-Alimentação e Auxílio-Gás) do Governo Fernando Henrique Cardozo (FHC).
}

mas que duram determinado período, se são apenas instrumentos sem políticas bem direcionadas ou ainda políticas com instrumentos ineficazes (ALMEIDA, 2008).

Nessa abordagem, percebemos a necessidade de trabalhos que visem avaliar e aprimorar o diálogo e a articulação desses programas e das instituições públicas envolvidas, com perspectiva de desenvolvimento local para a inclusão social e a capacidade de ação dos agentes envolvidos nessas políticas públicas.

O Bolsa Família é um programa conhecido nacional e internacionalmente. É alvo de muitas repercussões, positivas e negativas, pois seus resultados apresentam inúmeras indagações nos diversos segmentos em que atua (renda, saúde, educação, focalização, trabalho infantil, etc.). No caso deste trabalho, são discutidas questões em relação à segurança alimentar dos beneficiários do programa, principalmente ligadas à renda, tais como: se o programa vai além do acesso à renda e propicia elementos de segurança alimentar nas famílias assistidas; se o perfil de segurança alimentar dos beneficiários e a sua renda per capita familiar condizem com a necessidade de eles receberem o auxílio do programa; ou seja, como coloca Segall-Correa e Salles-Costa (2008), há que se pensar em que medida o acesso aos recursos financeiros por intermédio de programas de transferência de renda, no caso o Bolsa Família, amplia as possibilidades da segurança alimentar das famílias mais vulneráveis.

Diante das informações apresentadas, o trabalho buscou discorrer sobre as repercussões (efeitos) $)^{4}$ do Programa Bolsa Família, tendo como recorte analítico elementos de $\mathrm{SAN}^{5}$ tratada de maneira ampla, relativa aos

\footnotetext{
${ }^{4}$ Os efeitos de uma política sobre a sociedade não se limitam àqueles que foram previstos e são esperados ou, pelo menos, desejados, de acordo com seus objetivos. A avaliação deve considerar os efeitos colaterais, sejam eles positivos ou negativos, que a política pode acarretar. É necessário apreciar todos os efeitos (de uma política sobre a sociedade) que foram produzidos com a ação, sejam eles de caráter técnico, econômico e social ou positivos e negativos (CONSEIL DE L'ÉVALUATION, 1996; GUÉNEAU, 2001 apud ALMEIDA, 2008).

5 São elementos ou variáveis de análise de segurança alimentar: o nível de Insegurança Alimentar, o perfil da renda, escolaridade, saúde, trabalho, entre outros, os quais serão discutidos mais adiante.
} 
beneficiários no município de Araraquara/ SP. A partir disso, espera-se fornecer subsídios importantes para uma reflexão mais aprofundada sobre o funcionamento do programa local e nacional.

A seguir, apresenta-se uma breve revisão teórica sobre o processo de avaliação de políticas públicas e o conceito mais amplo da temática da segurança alimentar. Em seguida, são detalhados os procedimentos e instrumentos metodológicos utilizados na pesquisa. Posteriormente, são analisados e discutidos os resultados da pesquisa e, por fim, são colocadas as considerações finais.

\section{O processo de avaliação de políticas públi- cas: um desafio não resolvido?}

Dentro do estudo sistemático das políticas públicas, Lasswell (1956 apud SOUZA, 2006) apresentou um modelo teórico de estágios ou ciclos chamado de policy cicle ou ciclo de políticas públicas, no qual buscava explicações sobre o processo de produção de políticas. Após algumas considerações de autores distintos, os estágios resumiram-se às seguintes fases: agenda-setting (quando um problema chama a atenção de uma política), formulação (quando o governo formula as opções para um problema), decisão (escolha das opções; é determinado um curso de ação ou não ação), implementação (quando o governo coloca ação em prática) e avaliação (os resultados da política são monitorados pelo governo e por atores sociais), sendo esta última o foco do presente trabalho.

O trabalho de Belloni, Magalhães e Souza (2001) procura descrever uma metodologia de avaliação em políticas públicas com base em uma experiência na educação profissional, ou seja, apresenta concepções e distinções entre a avaliação educacional, institucional e de políticas públicas. Portanto o conceito de avaliação adotado pelos autores refere-se à análise de processos, produtos ou resultados de atividades ou ações desenvolvidas, ou seja, de programas ou políticas. Para eles, essa modalidade carece de maior aprofundamento teórico e metodológico; assim, propõe-se a definição de avaliação:

A avaliação é uma forma de pesquisa social aplicada, sistemática, planejada e dirigida; destina-se a identificar, obter e proporcio- nar de maneira válida e confiável dados e informações suficientes e relevantes para apoiar um juízo sobre o mérito e o valor dos diferentes componentes de um programa (tanto na fase de diagnóstico, programação e execução) ou de um conjunto de atividades específicas que se realizam, foram realizadas ou se realizarão, com o propósito de produzir efeitos e resultados concretos; comprovando a extensão e o grau em que se deram estas conquistas, de tal forma que sirva de base ou para uma tomada de decisões racional e inteligente entre cursos de ação, ou para solucionar problemas e promover o conhecimento e a compreensão dos fatores associados ao êxito ou fracasso de seus resultados. (AGUILLAR; ANDEREGG, 1994 apud BELLONI; MAGALHÃES; SOUZA, 2001, p. 20-21).

Assim, os autores enfatizam que a avaliação deve abranger o processo de formulação e implementação das ações e os resultados, tornando-se instrumento fundamental para o aperfeiçoamento ou reformulação das ações desenvolvidas. Do mesmo modo como apresenta Almeida (2008), a avaliação tem sido instrumento de gestão valioso para o conhecimento e a viabilização de programas e projetos, para o redirecionamento, quando se fizer necessário, de seus objetivos, até mesmo para a reformulação de rumos e propostas, fornecendo subsídios para tomadas de decisão.

Almeida (2008) diz que a análise ou a avaliação de políticas públicas não é simplesmente um instrumento de aperfeiçoamento ou redirecionamento dos programas empreendidos pelo governo, mas especialmente, uma ferramenta capaz de prestar contas à sociedade das ações governamentais; bem como Santos e Santos (2007), que destacam a necessidade de se executar políticas sociais que maximizem a eficiência, a participação da comunidade e a focalização.

Para tanto, é preciso aprimorar o monitoramento e avaliação de programas, contemplando a avaliação dos processos, dos impactos e da eficiência das ações. "A avaliação de políticas e programas tornou-se um compromisso tanto quanto um desafio" (SANTOS; SANTOS, 2007, p. 1029), pois no Brasil a experiência sobre avaliação de programas de combate à fome e à pobreza é ainda pouco significativa e sistemática, e não muito extensa. Como por exemplo, de acordo com 
Santos e Santos (2007), nos anos 70, aspectos do II Programa Nacional de Alimentação e Nutrição (II PRONAN) foram sujeitos à avaliação, mas essas tentativas não se aprofundaram na análise da dimensão e das implicações do programa como uma política pública.

No entanto, nos últimos anos, esse quadro vem mudando, mesmo que lentamente, pois em virtude das grandes demandas da sociedade e da escassez dos recursos públicos, "torna-se imprescindível a busca de instrumentos que possibilitem maximizar os resultados sociais dos programas governamentais" (SILVA NETO; MELO; PEREIRA, 2006, p. 1).

\section{O conceito de segurança alimentar e nu- tricional: uma resposta à vulnerabilidade social?}

O conceito de segurança alimentar foi constituído a partir do final da Segunda Grande Guerra Mundial (1945) com a crise dos agricultores em grande parte dos países industrializados. Esse conceito levou a um melhor conhecimento da situação alimentar sob três aspectos: quantidade, qualidade e regularidade no acesso aos alimentos (BELIK, 2003).

Segundo o autor, cabe ressaltar o conceito desses aspectos. $\mathrm{O}$ acesso aos alimentos diferencia-se da disponibilidade dos alimentos, ou seja, os alimentos podem estar disponíveis, mas não acessíveis à camada mais pobre da população. A qualidade refere-se a consumir os alimentos com dignidade (sem riscos de contaminação ou apodrecimento); e a regularidade diz respeito ao acesso constante à alimentação (pelo menos três vezes ao dia).

Na década atual o Brasil tem vivenciado a incrustação de políticas públicas de segurança alimentar consideradas mais alternativas nos diversos âmbitos governamentais (federal, estadual e municipal). Os primeiros anos do século XX tornaram-se marcantes porque o conceito mais amplo de segurança alimentar finalmente começou a sustentar uma pauta de políticas públicas destinadas à redução da fome da população miserável e ao aumento de ações solidárias para pessoas em situações de marginalização no país (incluindo pessoas produtivas, como trabalhadores rurais, agricultores familiares etc.). Desde 1997, quando a Cúpula Mundial da Alimentação (uma arena de representação dos governos dos países vinculados à $\mathrm{ONU}$ ) finalmente conseguiu produzir em consenso um conceito $^{6}$ de segurança alimentar amplo para subsidiar políticas públicas aplicáveis nos mais diversos países (dos desenvolvidos aos subdesenvolvidos), alguns programas começaram a ser executados no Brasil. De lá para cá, os esforços de vários governos no Brasil (locais, estaduais e federais) produziram a efetivação de várias políticas de segurança alimentar. (PAULILLO; PESSANHA, 2002 apud ALMEIDA et al., 2006, p. 208-209).

As políticas de segurança alimentar devem responder por três dimensões: produção (nas áreas rurais e urbanas), distribuição (suplementar ou emergencial a grupos específicos), acesso (ações e comercialização) e consumo (educação alimentar e consumo sustentável) de alimentos; devem também estar ligadas a elementos e/ou valores fundamentais da população: a) saúde, b) higiene, c) meio ambiente, d) autenticidade e e) solidariedade.

Todos esses valores são socialmente construídos e compartidos em redes de políticas focadas para a funcionalidade e adaptação de um padrão alimentar com equidade para a população mal nutrida. (ALMEIDA et al., 2006, p. 209).

Ainda, de acordo com os autores, os valores ligados ao eixo da saúde referem-se a dimensões dietética e farmacêutica ligadas à composição nutricional dos alimentos: conteúdo proteico, fibras, colesterol etc. Para tanto, a educação alimentar da população mais vulnerável é fundamental. O eixo da higiene e seguridade dos alimentos engloba a ausência de tóxicos ou elementos nocivos, sendo necessárias informações, garantias e o controle sobre as condições da produção, distribuição e embalagens (certificação dos produtos). $\mathrm{O}$ meio ambiente está relacionado ao ecológico ou orgânico, produção sem tóxicos e respeito ao meio ambiente. Assim, sua preservação é

\footnotetext{
${ }^{6}$ A SAN diz respeito à "realização do direito de todos ao acesso regular e permanente de alimentos de qualidade, em quantidade suficiente, sem comprometer o acesso a outras necessidades essenciais, tendo como base práticas alimentares promotoras de saúde, que respeitem a diversidade cultural e que sejam social, econômica e ambientalmente sustentáveis" (BRASIL, 2006 apud SEGALL-CORREAA; MARIN-LEON, 2009, p. 11).
} 
fundamental. O eixo da autenticidade está ligado aos valores naturais e tradicionais da produção agroalimentar, aos conhecimentos muitas vezes herdados de práticas alimentares, à valorização da origem dos produtos e às especificações dos processos produtivos, ou seja, "são os ideais do saber fazer". E, por fim, o eixo da solidariedade envolve valores morais e ideológicos que impulsionam a participação da população bem nutrida em ações humanísticas no processo de consumo. São exemplos deste último o comércio justo internacional, os mercados institucionais municipais e os produtos agroindustriais familiares (PAULILLO; PESSANHA, 2002).

Os elementos trabalhados neste estudo remetem-se à Escala Brasileira de Medida de Insegurança Alimentar (EBIA) e suas associações com os eixos da saúde, relacionada a problemas crônicos de saúde dos beneficiários e da solidariedade, relacionada às suas vulnerabilidades, nas quais contam os fatores renda, consumo alimentar, escolaridade, trabalho e proteção social.

\section{Aspectos metodológicos: a construção da pesquisa}

No Estado de São Paulo, segundo a Secretaria Nacional de Renda e Cidadania (SENARC) do MDS$^{7}$ (BRASIL, 2010), cerca de mais de um milhão de famílias são atendidas pelo Bolsa Família, o que representa mais de $10 \%$ do total nacional. Tal montante demonstra que embora o estado seja um dos mais desenvolvidos do país, o contingente de população e a desigualdade social são agravantes que impõem à região uma posição socialmente debilitada.

O universo empírico, ou seja, o município de Araraquara está localizado na região Administrativa Central do Estado de São Paulo

\footnotetext{
${ }^{7}$ O MDS, criado em 2004 pelo presidente Lula, tem a missão de promover o desenvolvimento social e combater a fome visando à inclusão e à promoção da cidadania, garantindo a segurança alimentar e nutricional, uma renda mínima à cidadania e assistência integral às famílias. A SENARC, por meio do MDS, tem por objetivo a implementação da Política Nacional de Renda de Cidadania no país. Articula ações específicas dos programas de transferência de renda Federal, estaduais e municipais, estabelecendo a soma de esforços entre os entes federados e as demais ações sociais em curso (BRASIL, 2010).
}

(RA12), considerado o mais rico e de maior poder aquisitivo, com um elevado Índice de Desenvolvimento Humano Municipal (IDHM) e uma população estimada de 200.666 habitantes - SENARC, 2009 (BRASIL, 2010).

A Secretaria Municipal de Assistência e Desenvolvimento Social (SMADS) é o órgão responsável pelo PBF no município, juntamente com os Centros de Referência de Assistência Social (CRAS) - ou "casas da família", situadas em bairros de maior vulnerabilidade social - os quais se relacionam também com as Secretarias Municipais de Saúde, Educação (para o acompanhamento das condicionalidades do programa) e da Agricultura, com o Conselho Municipal de Segurança Alimentar e Nutricional (COMSAN), instância designada ao controle social do programa local, e com o Centro de Referência Especializado de Assistência Social (CREAS), responsável pela proteção social especial às famílias (crianças, jovens, mulheres, idosos) vítimas de violências.

A pesquisa de natureza aplicada utiliza métodos descritivos, de objetivo exploratório, com abordagens qualitativas e quantitativas. O objetivo exploratório da pesquisa partiu do levantamento bibliográfico de dados secundários da temática e do objeto de estudo a fim de ampliar, o mais detalhadamente possível, seu conhecimento. As abordagens qualitativas e quantitativas basearam-se na coleta de dados primários com as observações de campo e aplicação de formulários semiestruturados.

\section{População e amostra}

O tamanho da amostra, determinado com base na estimativa da proporção populacional ${ }^{8}$, foi definido com recorte apenas nos beneficiários $^{9}$ do Bolsa Família no município, sendo utilizada a amostragem estratificada pelos Centros de Referência de Assistência Social e pela Secretaria Municipal (Tabela 1).

\footnotetext{
${ }^{8}$ Ver: LEVINE; BERENSON; STEPHAN, Estatística: teoria e aplicações usando Microsoft Excel em português. Rio de Janeiro: LTC, 2000. 811p.

${ }^{9}$ De acordo com o Gestor local do programa (informação verbal), atualmente (julho de 2010) são aproximadamente 6.000 famílias cadastradas, mas cerca de 4.000 são beneficiárias.
} 
Tabela 1 - Tamanho da amostra de famílias beneficiárias pelas entidades responsáveis

\begin{tabular}{cccc}
\hline ENTIDADES & POPULAÇÃO & AMOSTRA & \% \\
\hline SMADS & 1853 & 46 & 2,5 \\
CRAS Selmi Dei & 700 & 18 & 2,6 \\
CRAS Parque São Paulo & 569 & 14 & 2,5 \\
CRAS Yolanda Ópice & 433 & 11 & 2,5 \\
CRAS Vale do Sol & 233 & 6 & 2,6 \\
CRAS Parque das Hortênsias & 212 & 5 & 2,4 \\
TOTAL & $\mathbf{4 0 0 0}$ & $\mathbf{1 0 0}$ & $\mathbf{2 , 5}$ \\
\hline
\end{tabular}

Fonte: Traldi (2011).

Na coleta e análise dos dados, as técnicas quantitativas foram baseadas na metodologia da Rede Interdisciplinar de Estudo e Pesquisa em Segurança Alimentar e Nutricional - Rede Alimenta ${ }^{10}$ da Universidade Estadual de Campinas (UNICAMP), no caso, os formulários aplicados às famílias beneficiárias do programa em etapa antecedente às técnicas qualitativas, ou seja, as observações de campo.

Os formulários constituem-se em 8 módulos referente às informações gerais do domicílio; à caracterização da segurança alimentar/fome dos maiores e menores de 18 anos de idade; às características sóciodemográficas dos titulares/chefes e membros das famílias; à caracterização do padrão de consumo alimentar do beneficiário; às condições de saúde e de trabalho; ao apoio e proteção social; à caracterização do trabalho e da renda da família; e em relação à inserção do programa na família.

Esses indicadores (sócio-demográficos e socioeconômicos) foram cruzados com os níveis de insegurança alimentar das famílias, resultando em algumas relações - compreendidas - apresentadas mais adiante nos resultados.

A pesquisa seguiu o protocolo de ética em pesquisa com seres humanos e foi apro-

\footnotetext{
${ }^{10} \mathrm{O}$ formulário da Rede Alimenta, o qual engloba o método da Escala Brasileira de Medida de Insegurança Alimentar (EBIA) - Módulo II do Formulário Pesquisa do Perfil sócio-demográfico e socioeconômico das famílias beneficiárias do Bolsa Família em Araraquara/SP - possibilita o cruzamento com variáveis sócio-demográficas, padrão de consumo alimentar, local de moradia, redes de proteção social, trabalho e renda, entre outras, que abrem brechas analíticas ao desenvolvimento do trabalho e ao programa em questão (ALMEIDA, 2008; PAULILLO et al., 2009).
}

vada pelo Comitê de Ética do Centro Universitário de Araraquara (UNIARA).

\section{A Escala Brasileira de Medida de Insegu- raça Alimentar (EBIA)}

Segundo Almeida (2008), tendo em conta a complexidade conceitual de segurança alimentar, sobretudo por ser abrangente e multidimensional, foram levantadas metodologias utilizadas em outros países (para acompanhar os níveis de segurança alimentar da população) no sentido de subsidiar a proposta de investigação para a realidade brasileira (países menos desenvolvidos). Dessa forma, o método utilizado na Pesquisa Nacional por Amostra de Domicílios (PNAD, 2004) foi baseado numa "concepção de escala de medida direta" do Departamento de Agricultura dos Estados Unidos da América (EUA) ${ }^{11}$.

Como resultado do processo de adaptação do método no Brasil foi elaborada e validada uma Escala Brasileira de Medida de Insegurança Alimentar (EBIA) pela UNICAMP, pelo Observatório de Políticas de Segurança Alimentar e Nutrição da Universidade de Brasília (UNB) e por outras instituições - Rede Alimenta $^{12}$.

\footnotetext{
${ }^{11}$ Nos EUA, o instrumento de medida chama-se Household Food Security Survey Module (HFSSM) e contém 18 itens, os quais apresentam indicadores referentes não somente à disponibilidade calórica por pessoa, mas ao acesso aos alimentos como: rendimentos, gastos com alimentação e consumo alimentar familiar (SEGALLCORRÊA; MARIN-LEON, 2009).

${ }^{12}$ A Rede Alimenta, uma rede interdisciplinar de estudo e pesquisa em segurança alimentar e nutricional, é fruto da interação de pesquisadores, gestores e representantes institucionais, estruturada para prover suporte descentralizado aos gestores de políticas públicas nos âmbitos federal, estadual e municipal.
} 
A EBIA é um método de mensuração da situação alimentar domiciliar, que objetiva captar distintas dimensões da Insegurança Alimentar (IA), desde o receio de sofrer a privação alimentar no futuro, passando pelo comprometimento da qualidade da dieta, limitação da qualidade de alimentos consumidos, até o nível mais grave de fome já atingido. É aplicado diretamente a uma pessoa da família, que seja responsável pela alimentação do domicílio, por meio de um questionário com 15 questões fechadas (Quadro 1) com respostas do tipo sim ou não referentes aos últimos três meses (SEGALLCORRÊA; SALLES-COSTA, 2008), ou seja, é uma escala que mede a percepção da pessoa de referência sobre a situação alimentar domiciliar. Segundo Segall-Corrêa e Salles-Costa (2008), essa escala permite a classificação das famílias em quatro categorias:
Segurança Alimentar (SA): quando não há restrição alimentar de qualquer natureza, nem mesmo a preocupação com a falta de alimentos no futuro;

$>$ Insegurança Alimentar Leve (IAL): quando há preocupação ou incerteza quanto ao acesso aos alimentos, portanto, risco para a sustentabilidade e, ainda, comprometimento da qualidade da dieta;

$>$ Insegurança Alimentar Moderada (IAM): quando aparecem restrições quantitativas especialmente relevantes entre pessoas adultas, e;

$>$ Insegurança Alimentar Grave (IAG): quando há redução importante da quantidade de alimentos disponíveis, tanto para a alimentação de adultos, como para a de crianças que residem no domicílio. Nesta última, há evidente quebra nos padrões usuais de alimentação das famílias, com alta possibilidade de ocorrência de fome.

\begin{tabular}{|ll|}
\hline 1. & Preocupação que a comida acabasse antes que tivesse condição de comprar mais. \\
\hline 2. & A comida acabou antes que tivesse dinheiro para comprar mais? \\
\hline 3. & Ficou sem dinheiro para ter uma alimentação saudável e variada? \\
\hline 4. & $\begin{array}{l}\text { Dispõe de apenas alguns tipos de alimentos para alimentar os(as) moradores(as) com } \\
\text { menos de } 18 \text { anos porque o dinheiro acabou? }\end{array}$ \\
\hline $\begin{array}{l}\text { 5. } \\
\text { Adulto(a) diminuiu a quantidade de alimentos ou pulou refeições porque não havia } \\
\text { dinheiro para comprar comida? }\end{array}$ \\
\hline 6. & $\begin{array}{l}\text { Comeu menos do que achou que devia porque não havia dinheiro suficiente para } \\
\text { comprar comida? }\end{array}$ \\
\hline 7. & Entrevistado(a) sentiu fome, mas não comeu porque não podia comprar comida? \\
\hline 8. & $\begin{array}{l}\text { Entrevistado(a) perdeu peso porque não tinha dinheiro suficiente para comprar } \\
\text { comida? }\end{array}$ \\
\hline 9. & $\begin{array}{l}\text { Adulto(a) ficou um dia inteiro sem comer ou teve apenas uma refeição ao dia porque } \\
\text { não havia dinheiro para comprar comida? }\end{array}$ \\
\hline $\begin{array}{l}\text { 10. } \\
\text { Não pôde oferecer a algum(a) morador(a) com menos de } 18 \text { anos alimentação } \\
\text { saudável e variada porque não tinha dinheiro? }\end{array}$ \\
\hline $\begin{array}{l}\text { 11. Algum(a) morador(a) com menos de } 18 \text { anos não comeu em quantidade suficiente } \\
\text { porque não havia dinheiro para comprar comida? }\end{array}$ \\
\hline $\begin{array}{l}\text { 12. } \\
\text { Diminuiu a quantidade de alimentos das refeições de algum(a) morador(a) com menos } \\
\text { de 18 anos porque não havia dinheiro suficiente para comprar comida? }\end{array}$ \\
\hline $\begin{array}{l}\text { 13. Algum(a) morador(a) com menos de } 18 \text { anos deixou de fazer alguma refeição porque } \\
\text { não havia dinheiro para comprar comida? }\end{array}$ \\
\hline $\begin{array}{l}\text { 14. Algum(a) morador(a) com menos de } 18 \text { anos teve fome, mas você simplesmente não } \\
\text { podia comprar mais comida? }\end{array}$ \\
\hline $\begin{array}{l}\text { 15. Algum(a) morador(a) com menos de } 18 \text { anos ficou sem comer por um dia inteiro } \\
\text { porque não havia dinheiro para comprar comida? }\end{array}$ \\
\hline
\end{tabular}

Quadro 1 - Perguntas utilizadas para avaliar a insegurança alimentar a partir da EBIA

Fonte: Segall-Correa e Salles-Costa (2008). 
A pontuação para a classificação dos níveis de segurança ou insegurança alimentar (categorias descritas acima) das famílias entrevistadas neste estudo dá-se pela somatória de valor 1 para cada resposta afirmativa/ positiva e, a seguir, os pontos de corte que definem os diferentes estratos, como mostra a tabela abaixo:

Tabela 2 - Classificação dos níveis de Insegurança Alimentar (IA)

\begin{tabular}{c|c|c}
\hline \multirow{2}{*}{ Classificação } & \multicolumn{2}{|c}{ N. de respostas afirmativas/positivas } \\
\cline { 2 - 3 } & Famílias com menores de 18 anos & Famílias com pessoas adultas \\
\hline S A & 0 & 0 \\
\hline IAL & 1 a 5 & 1 a 3 \\
\hline IAM & 6 a 10 & 4 a 6 \\
\hline IAG & 11 a 15 & 7 a 8 \\
\hline
\end{tabular}

Fonte: Segall-Correa e Salles-Costa (2008).

A disseminação do uso da EBIA no território nacional, pelo portal da Rede Alimenta, permite identificar localidades e grupos de maior risco de IA, bem como acompanhar e avaliar o cumprimento de metas das políticas pertinentes e medir seu impacto populacional (ALVES FILHO, 2006), o que mostrou a PNAD 2004, quando foi realizado o primeiro diagnóstico no Brasil de segurança e insegurança alimentar, o qual apresentou que cerca de $40 \%$ da população brasileira convivia com algum grau de insegurança alimentar (SEGALL-CORREAA; MARIN-LEON; 2009).

Segundo as autoras, as informações da PNAD 2004 mostraram ainda que:

[...] os usuários do programa Bolsa Família (BF) apresentavam prevalências mais altas $(14,9 \%)$ de insegurança alimentar grave, mais que o dobro da observada na média nacional. Isto levantou, à ocasião, polêmica com algumas hipóteses nos jornais diários sobre uma suposta baixa eficiência do programa. Entendeu-se, entretanto, como mais plausível, que a população de usuários concentrava condições outras de vulnerabilidade que reduziam o impacto da transferência de renda. Essa hipótese foi confirmada ao ser analisada, por meio de modelagem estatística adequada, as mudanças ocorridas no perfil de segurança alimentar a partir do acréscimo de renda oriundo do programa. Observou-se que a cada 10 reais de acréscimo na renda familiar, por meio do BF, a chance de segurança alimentar aumentava em $8 \%$. Isto significa que a cada 60 reais, perto do valor médio de transferência à época, uma chance de cerca de $50 \%$ de mudança de status, passando o domicílio de situação de insegurança para a segurança alimentar. (SEGALL-CORRÊA; MARIN-LEON, 2009, p. 9-10).

O artigo de Segall-Corrêa e Marin-Leon (2009) descreve os resultados do uso da EBIA a partir de seu processo de validação até os inquéritos de abrangência nacional, sua utilização pelos gestores municipais e para a produção acadêmica; justifica ainda a relevância dessa escala como instrumento auxiliar das políticas públicas de combate à fome no Brasil, "um problema que aparentemente se mantém na sombra, para muitos, escondido no eufemismo de população vulnerável ou de risco de insegurança alimentar" (SEGALLCORREA, MARIN-LEON, 2009, p. 13).

\section{Resultados e discussões}

\section{Perfil dos beneficiários}

Como ocorre na maioria de outras pesquisas, a maior porcentagem dos titulares do programa são mulheres (94\%) - pois existe um 'consenso' tanto por parte dos beneficiários quanto de gestores sobre a titularidade do cartão ser concedida preferencialmente às mulheres $^{13}$ - e também, na maior parte dos

\footnotetext{
${ }^{13}$ Em outras pesquisas (INSTITUTO BRASILEIRO DE ANÁLISES SOCIAIS E ECONÔMICAS, 2008), a razão é pelo fato de que as mulheres conhecem melhor as necessidades da família e porque tendem a gastar o beneficio com alimentação e com os filhos.
} 
casos são mães solteiras (separadas) com crianças (49\%), porém Araraquara apresentou uma alta porcentagem de titulares mulheres com companheiros e crianças (42\%).

Em relação à escolaridade, a maioria dos titulares sabe ler e escrever, mas apresentam ainda baixos graus de escolaridade: $67 \%$ têm o ensino fundamental, e $8 \%$ têm o ensino médio incompleto, sendo apenas $20 \%$ com ensino médio completo e uma baixíssima porcentagem com ensino superior (3\%). Em $39 \%$ das famílias, a maior escolaridade é o fundamental; e, em $76 \%$, há pelo menos de um a três menores de 18 anos estudantes.

A metade das famílias (51\%) respondeu que existia pelo menos uma pessoa com algum problema crônico de saúde, como diabetes e/ou hipertensão, ou seja, grande parte ainda necessita de cuidados em relação à saúde, a partir do que se pode concluir que existe um precário acompanhamento da saúde por parte do programa, uma das condicionalidades. Já em relação ao acesso a bens públicos básicos, como rede de esgoto, energia, coleta de lixo e distribuição de água são aspectos favoráveis às famílias, o que não acontece normalmente em muitos casos, mas, com isso, o município de Araraquara mostra estar avançando em relação às condições de saneamento.

Em relação à situação de trabalho dos titulares das famílias, somente $14 \%$ trabalham permanente, ou seja, têm registro em carteira; $40 \%$ trabalham sem registro em carteira (temporariamente ou por conta própria) e $30 \%$ estão desempregados, procurando emprego. O percentual de titulares autônomos e desempregados é elevado, o que descaracteriza, para alguns, o programa quanto à proposta de evitar as práticas assistencialistas. No entanto, de acordo com outras pesquisas (INSTITUTO BRASILEIRO DE ANÁLISES SOCIAIS E ECONÔMICAS, 2008), o fato de os titulares serem, na maioria, mulheres pode explicar o baixo índice de trabalhadores permanentes, pois as mulheres dedicam-se mais à gestão da casa.

A renda média total das famílias advindas de todas as formas de remuneração (bolsa família, trabalho, pensão ou aposentadoria) mostra que mais da metade das famílias (64\%) possuem renda menor do que um salário mínimo (510,00 reais), e apenas 36\% recebem igual ou mais do que um salário mínimo.

Em relação ao padrão de consumo alimentar, a maioria dos titulares tomam café da manhã (53\%), almoçam (82\%) e jantam (77\%) nos 7 dias da semana. A porcentagem do café da manhã é mais baixa, pois muitos relataram tomar apenas um pouco de "café preto" e muitos não são acostumados a fazer a refeição matinal e, em alguns casos, afirmaram nem sempre ter dinheiro para o pão.

Das famílias que possuem crianças frequentando escolas ou creches, $51 \%$ recebem em média uma vez ao dia refeição escolar, 35\% recebem em média duas ou mais vezes ao dia, sendo apenas $1 \%$ que não recebe e, em $13 \%$ das famílias, não se aplicava a questão, pelo fato de que não tinham crianças menores de 14 anos; ou seja, a merenda escolar é complementar para $87 \%$ das famílias com menores de 14 anos, o que pode contribuir, mesmo que indiretamente, para a melhora dos níveis de insegurança alimentar; além de ser importante para o orçamento doméstico (menos gastos em casa com alimentação das crianças), de acordo com o Instituto Brasileiro de Análises Sociais e Econômicas (2008).

Grande porcentagem das famílias paga suas compras relacionadas às despesas alimentares à vista $(84 \%)$, não possuem dívidas com essas despesas $(67 \%)$, pois afirmam não querer se "afundar em dívidas".

A maioria das famílias (60\%) recebe ajuda em forma de alimento de entidades sociais, amigos, parentes, programas municipais e estaduais, entre outros; $40 \%$ não recebem nenhum tipo de ajuda. Desses $60 \%, 78 \%$ recebem de forma esporádica e $22 \%$ regularmente; a maioria ( $47 \%$ ) recebe cesta básica e $12 \%$ recebem leite (em pó e saquinho); nota-se que a minoria recebe mais de um tipo de ajuda em forma de alimento.

As doações da ajuda em forma de alimento são, na maioria (45\%), advindas da Assistência Social do município (cesta básica e leite), sendo o restante das igrejas, das próprias famílias dos beneficiários e de amigos. De acordo com o Instituto Brasileiro de Análises Sociais e Econômicas (2008), a solidariedade entre a população gera rede de apoio em situações de escassez alimentar.

Em questão de ajuda financeira, as famílias recebem em maior porcentagem (67\%) 
recursos somente advindos do Bolsa Família, e $20 \%$ recebem, além do Bolsa Família, o programa Estadual Renda Cidadã.

Os principais gastos das famílias com os benefícios do Bolsa Família são na maioria com a alimentação (69\%), com material escolar $(14 \%)$ e com vestuário (5\%) das crianças e adolescentes (roupas, uniformes e acessórios), resultado que é visto também em outras pesquisas na mesma ordem, o que mostra que o benefício está sendo bem direcionado.

\section{Insegurança alimentar e Bolsa Família}

Em relação à situação alimentar, 95\% das famílias beneficiadas pelo Programa Bolsa Família no município de Araraquara, SP apresentaram algum grau de insegurança alimentar - IA (Gráfico 1). Desse percentual, $26 \%$ encontram-se com IA grave, ou seja, há a fome extrema entre adultos e/ou crianças.

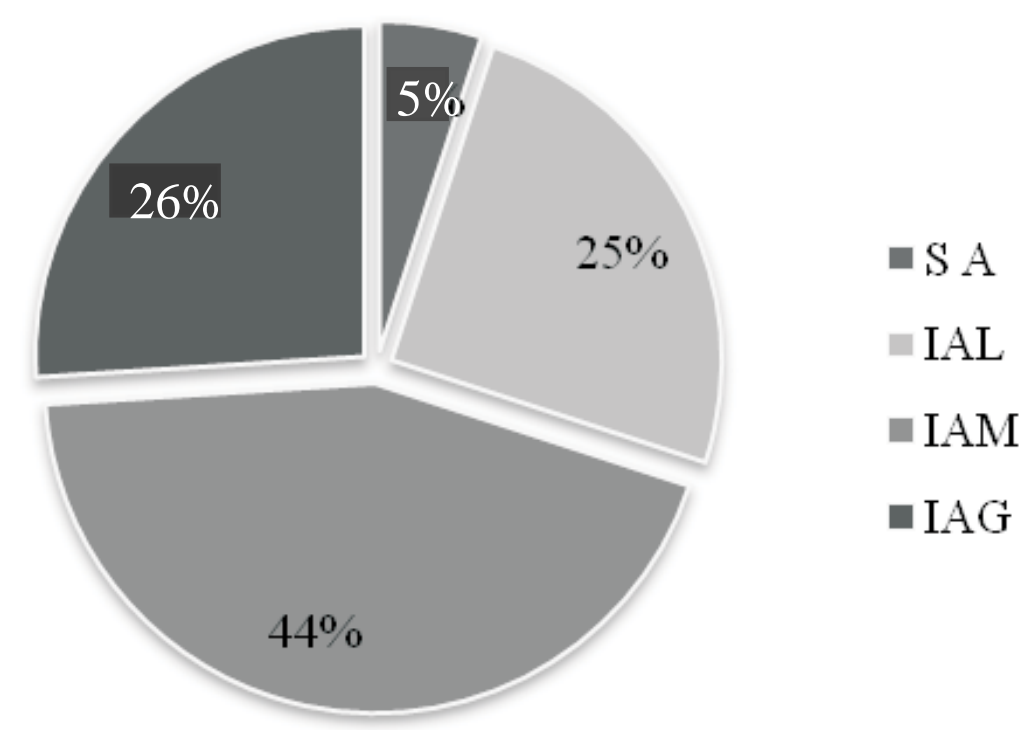

Gráfico 1 - Distribuição das famílias beneficiárias de acordo com a EBIA

Fonte: Traldi (2011)

O nível de IA mais grave é predominante nas famílias em que os titulares não sabem ler e escrever, os chefes são pensionistas, trabalhadores temporários ou sem emprego; nos que afirmam ter algum problema crônico de saúde, como diabetes ou hipertensão (bem como também é elevado o nível nos que afirmam não ter) e as famílias que recebem ajuda em forma de alimento (do Bolsa Família, e de parentes e amigos). A menor prevalência de IAG ocorre nas famílias que gastam mais os benefícios do programa com a alimentação.

Em relação à renda (Gráfico 2), nas famílias com renda média do Bolsa Família maior que $\mathrm{R} \$ 83,50$ (média total), prevalecem os níveis de IAG e IAM e, nas que possuem renda menor do que a média total, prevalecem o nível de IAL e a SA, o que leva à constatação de que o benefício está direcionado às famílias que mais necessitam (que apresentam os mais altos níveis de IA). 


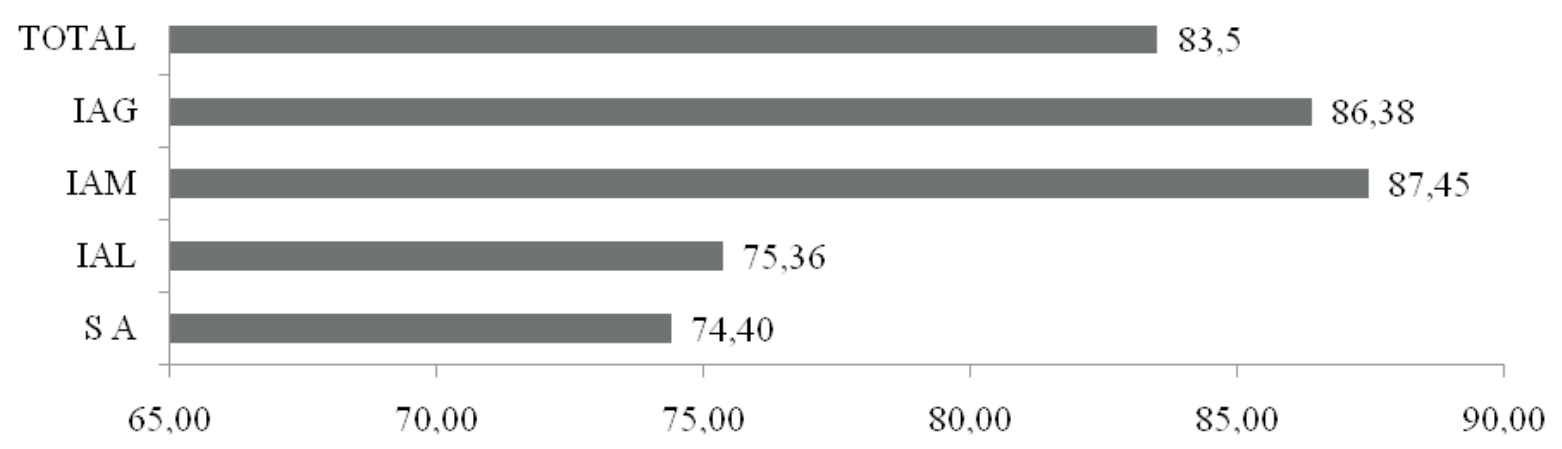

Gráfico 2 - Relação entre a renda média do Bolsa Família das famílias beneficiárias e o nível de insegurança alimentar

Fonte: Traldi (2011)

As famílias gastam em média um total de $\mathrm{R} \$ 233,95$ com alimentação. As famílias que gastam mais do que a média apresentam níveis de SA e IAL e as famílias que gastam menos do que a média total apresentam níveis de IAG e IAM (Gráfico 3).

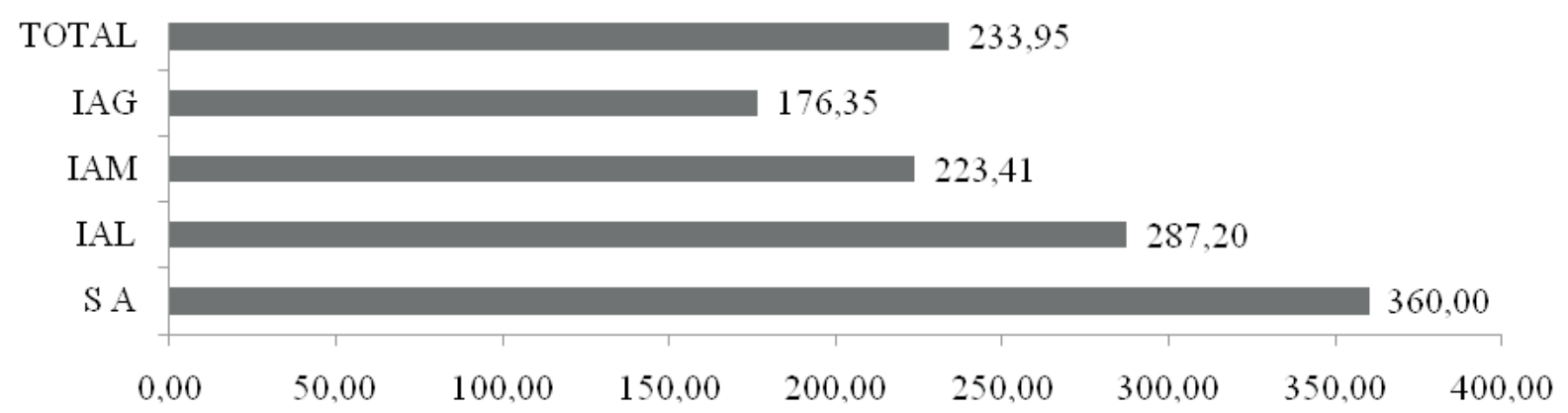

Gráfico 3 - Relação entre o gasto médio com alimentação das famílias beneficiárias e o nível de insegurança alimentar

Fonte: Traldi (2011)

O Gráfico 4 mostra que a SA é predominante nas famílias que têm uma renda média total de $\mathrm{R} \$ 822,40$, ou seja, quase o dobro do que a média total ( $\mathrm{R} \$ 421,84)$. Os níveis de IAM e IAG prevalecem nas famílias com renda média abaixo da média total.

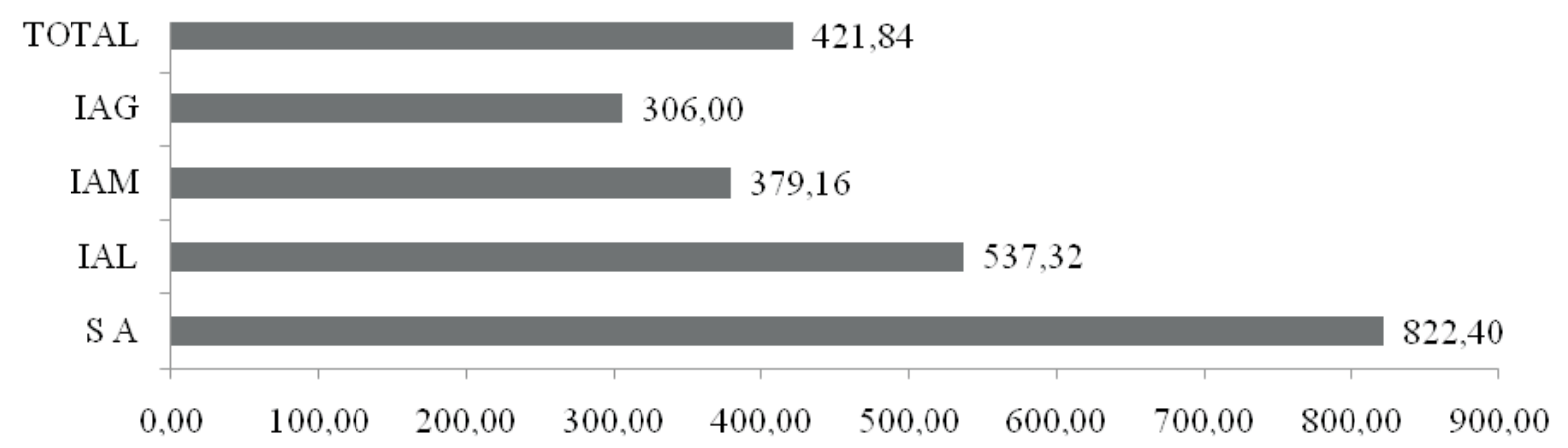

Gráfico 4 - Relação entre a renda média total das famílias beneficiárias e o nível de insegurança alimentar

Fonte: Traldi (2011) 
A porcentagem da renda média do Bolsa Família sobre renda média total das famílias (Gráfico 5) é de 43\% (quase a metade).
As famílias em que os benefícios do programa representam maior porcentagem apresentam os níveis de IA mais graves (IAG e IAM).

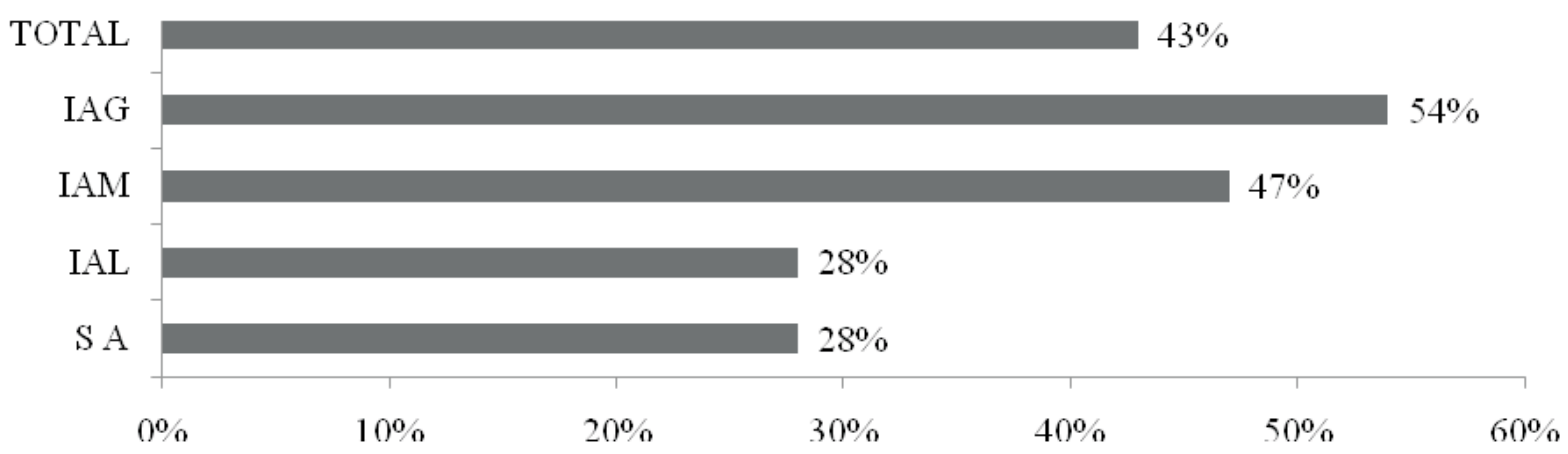

Gráfico 5 - Relação entre a porcentagem da renda média do Bolsa Família sobre a renda média total das famílias beneficiárias e o nível de insegurança alimentar

Fonte: Traldi (2011)

A maioria das famílias gasta mais do que recebe com a alimentação. A porcentagem do gasto médio com alimentação sobre a renda média total das famílias é de 109\%. Novamente é constatado que as famílias que gastam mais com alimentação são as que apresentam maiores níveis de IA. Todas as famílias que apresentam algum grau de insegurança alimentar gastam com alimentação acima de suas rendas familiares, portanto, indícios de formação de redes de cooperação e proteção social no município (Gráfico 6).

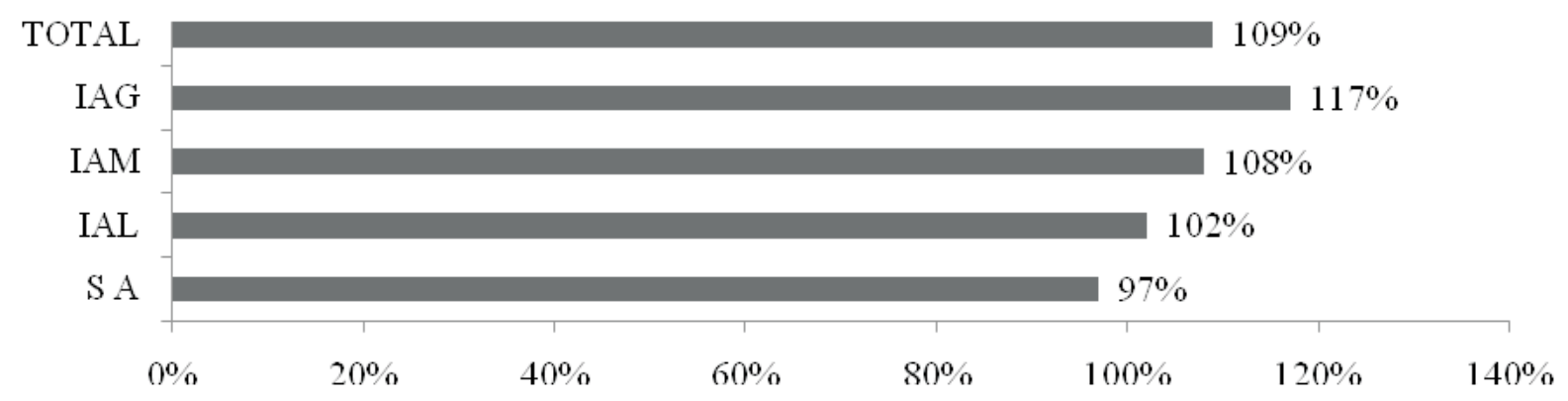

Gráfico 6 - Relação entre a porcentagem do gasto médio com alimentação sobre a renda média total das famílias beneficiárias e o nível de insegurança alimentar

Fonte: Traldi (2011)

A porcentagem da renda média do Bolsa Família sobre o gasto médio com alimentação é de $49 \%$. As famílias em que os benefícios têm maior representatividade nos gastos com alimentação são as que apresentam os níveis mais altos de IA. Famílias com insegurança alimentar moderada ou grave têm a renda proveniente do programa responsável por mais da metade gasta com alimentação, sinalizando o efeito significativo sobre a segurança alimentar dos beneficiários (Gráfico 7). 


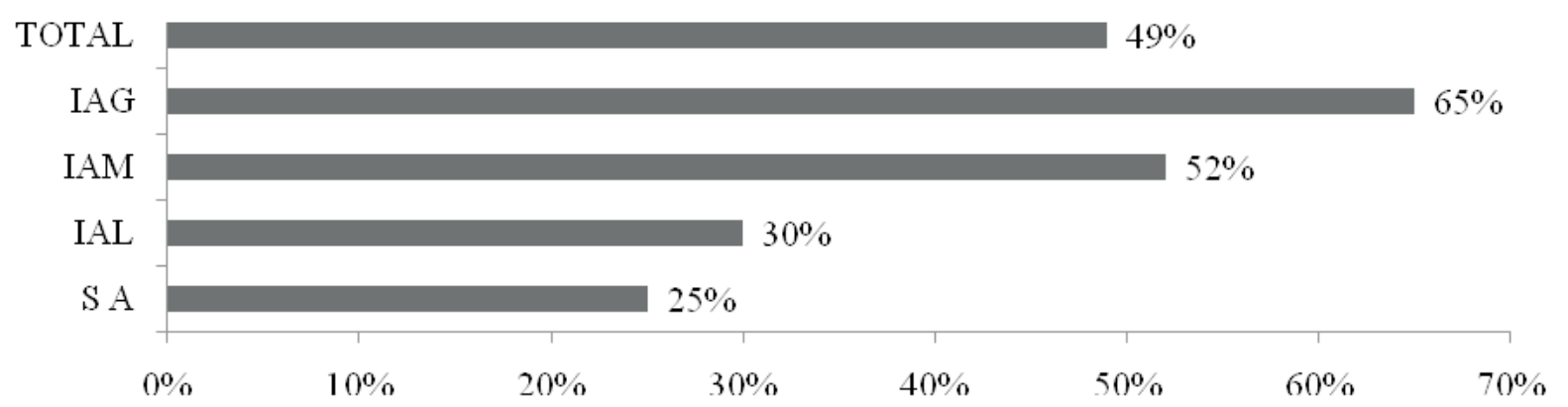

Gráfico 7 - Relação entre a porcentagem da renda média do Bolsa Família sobre o gasto médio com alimentação das famílias beneficiárias e o nível de insegurança alimentar

Fonte: Traldi (2011)

\section{Inserção do programa na família: embriões de inclusão social}

Em relação ao tempo de inserção no programa e aos benefícios, a maioria das famílias estão inseridas no programa anterior a $2009(84 \%)$, sendo $45 \%$ até 2 anos e meio, e $41 \%$ de 3 a 5 anos; $55 \%$ das famílias afirmam que o benefício foi interrompido pelo menos uma vez, na maioria das vezes por falta de atualização cadastral. Grande porcentagem (65\%) das famílias diz que o benefício não é suficiente e deveria aumentar uma média de 98,34 reais, sendo $58 \%$ na faixa de 20 a 80 reais, e $36 \%$ de 90 a 150 reais.

Em relação à renda total familiar, 40\% dos titulares afirmam que chegam ao final do mês com muita dificuldade; 33\% com dificuldade e $22 \%$ com alguma dificuldade. Mas, $61 \%$ das famílias avaliam o programa como sendo bom, e $25 \%$, como muito bom, pois, segundo eles, é uma "ajudinha a mais".

Quanto ao conhecimento do programa, $75 \%$ das famílias afirmam não conhecer a fundo sobre o programa, suas condicionalidades e benefícios; $17 \%$ afirmam conhecer mais ou menos. Isso mostra que há a falta de interesse por parte dos beneficiários, pois, segundo o gestor local, há vários meios de comunicação (rádio, folders, palestras) por parte da gestão.

As entidades responsáveis pelo programa local são bem vistas pelas famílias (76\%), sendo que os CRAS, na maioria das vezes, são bem mais elogiados.

Mais da metade das famílias (54\%) considera forte o esforço das entidades em manter os beneficiários dentro do programa; $97 \%$ acham que elas são fundamentais para o benefício chegar até eles. A maioria dos entrevistados $(99 \%)$ procuram as entidades quando têm algum problema, $89 \%$ dizem que elas ajudam a resolver o problema de forma adequada, principalmente os CRAS.

\section{Considerações finais}

De modo geral, as repercussões (efeitos) do Programa Bolsa Família no município de Araraquara podem ser diagnosticadas, num primeiro momento, considerando aspectos relevantes referentes ao perfil das famílias beneficiárias; às questões sócio-demográficas e socioeconômicas nas quais elas estão inseridas; ao alto percentual (95\%) de Insegurança Alimentar (IA) identificado na pesquisa, através da Escala Brasileira de Medida de Insegurança Alimentar; ao funcionamento do programa local.

As características das famílias entrevistadas encontram-se na maior parte em situações adversas: $29 \%$ das famílias pagam aluguel, sendo que mais da metade $(64 \%)$ ganha menos de um salário mínimo, 30\% não têm trabalho com registro em carteira (trabalha por conta própria), $30 \%$ estão desempregados, procurando emprego e a maior parte gasta muito mais do que recebe com alimentação (e, ainda assim, o grau de IA é elevado); o baixo grau de escolaridade, sendo que $38 \%$ têm o ensino fundamental incompleto ( $5^{\mathrm{a}}$ a $8^{\mathrm{a}}$ série); constatou-se a existência de algum problema crônico de saúde como diabetes e hipertensão em $51 \%$ das famílias; a dependência de ajuda financeira e de alimentos como cestas básicas e leite (em pó e saquinho) distribuídos pela Assistência Social, igrejas, familiares, amigos, 
entre outros; grande parte das famílias são chefiadas por mulheres e mães separadas.

Em relação à situação alimentar, o alto índice de IA divide-se em $44 \%$ em situação de Insegurança Alimentar Moderada (IAM), 25\% em situação de Insegurança Alimentar Leve (IAL), 26\% em situação de Insegurança Alimentar Grave (IAG) e apenas 5\% encontramse em Segurança Alimentar (SA). Destacandose a associação dos níveis à renda, nota-se que, nas famílias em que os benefícios do programa têm maior representatividade e em que os maiores gastos são com a alimentação, são as que possuem os níveis mais altos de IA, o que mostra que o programa está sendo bem direcionado.

Nos diários de campo, conforme foram sendo aplicados os formulários aos beneficiários, eram anotadas observações em relação ao programa e a eles. Constatou-se a falta de investimento nos Centros de Referência de Assistência Social, o que prejudica os atendimentos, reuniões do programa e acompanhamento da evolução das famílias beneficiárias; a falta de conhecimento e, muitas vezes, de interesse pelo programa por parte dos beneficiários; problemas com as condicionalidades do programa, principalmente com referência à frequência escolar das crianças e adolescentes. Há outras situações adversas que algumas famílias enfrentam em relação a preconceitos, problemas graves de saúde e adaptação local, problemas em conseguir emprego, dentre outros.

Assim, os resultados desta pesquisa alertam para a importância da integração do PBF com outros programas sociais para o melhoramento da situação de segurança alimentar (por 95\% das famílias estarem com IA); das condições de saúde (por mais da metade das famílias apresentarem problemas crônicos de saúde); educação (pelo baixo grau de escolaridade); capacitação (pela grande porcentagem de titulares sem registro em carteira e desempregados); e principalmente na alimentação, visto que os maiores gastos das famílias são com alimentos, nos quais os benefícios do programa têm grande representatividade, principalmente nas famílias com os níveis mais altos de IA.

Há a necessidade também de um maior esforço em relação ao conhecimento do programa, principalmente por parte dos beneficiários, pois é um aspecto que dificulta a inserção das famílias em outros programas sociais, ou seja, faz-se necessário estabelecer e intensificar estratégias de comunicação entre os beneficiários, gestores locais e sociedade; repensar os compromissos das condicionalidades, inserindo a questão da segurança alimentar dos beneficiários; a integração com políticas que possibilitem gerar oportunidades de emprego, de trabalho e renda, elementos necessários à real emancipação das famílias.

Apesar dos aspectos vulneráveis, os dados são bem significativos na constatação de que programas que se afirmam como políticas públicas compensatórias têm cumprido um papel inegável no enfrentamento à exclusão social. Conclusão que não pode ser lida como uma dogmática profissão de fé a favor do programa Bolsa Família, o qual deve constar de uma ajuda continuada de pesquisas e avaliações sobre suas consequências no âmbito familiar e no espaço público.

\section{Referências}

ALMEIDA, L. M. M. C. Estrutura de governança e gestão das redes e programas de segurança alimentar: análise comparativa entre municípios paulistas. Campinas, SP: UNICAMP - Faculdade de Engenharia Agrícola, 2008. 220 p. Relatório TécnicoCientífico de Bolsa de Pós-Doutorado no país.

ALMEIDA, L. M. M. C. et al. Políticas públicas, redes de segurança alimentar e agricultura familiar: elementos para construção de indicadores de eficácia. Estudos Sociedade e Agricultura, Rio de Janeiro, v. 14, n. 2, p. 205-235, 2006.

ALVES FILHO, M. Lançado portal para diagnosticar a real dimensão da fome no Brasil. Jornal UNICAMP, Campinas, p. 4, 20 fev. 2006. Disponível em: <http://www.unicamp.br/ unicamp/ unicamp_hoje/jornalPDF/ju313pg04.pdf > . Acesso em: 15 set. 2009.

BELIK, W. Perspectivas para segurança alimentar e nutricional no Brasil. Saúde e Sociedade, São Paulo, v. 12, n. 1, p. 12-20, jan./jun. 2003.

BELLONI, I.; MAGALHÃES, H.; SOUZA, L. C. Metodologia de avaliação em políticas públicas: uma experiência em educação profissional. 2. ed. São Paulo: Cortez, 2001. 95p. (Coleção Questões da Nossa Época, v. 75).

BRASIL. Instituto Brasileiro Geografia e Estatística - Pesquisa Nacional por Amostra de Domicílios. Brasília: IBGE, 2004. 
BRASIL. Ministério do Desenvolvimento Social e Combate à Fome. O Ministério. Disponível em: <http://www.mds.gov.br/sobreoministerio/ institucional>. Acesso em: 2 jul. 2010 .

. Programa Bolsa Família. Disponível em: <http://www.mds.gov.br/bolsa familia>. Acesso em: 12 ago. 2010.

BURLANDY, L. Transferência condicionada de renda e segurança alimentar e nutricional. Ciência $\mathcal{E}$ Saúde Coletiva, Rio de Janeiro, v. 12, n. 6, p. 14411451, nov./dez. 2007.

INSTITUTO BRASILEIRO DE ANÁLISES SOCIAIS E ECONÔMICAS (IBASE). Repercussões do Programa Bolsa Família na Segurança Alimentar e Nutricional das famílias beneficiadas. Relatório Técnico (preliminar). Rio de Janeiro: IBASE, 2008. 273p.

MESQUITA, C. S. O programa bolsa família: uma análise de seu impacto e significado social. 2007. 139f. Dissertação (Mestrado em Política Social) Universidade de Brasília (UNB), Brasília, DF, 2007.

PAULILLO, L. F. O. et al. Eficácia e coesão social do projeto Viva Leite: uma avaliação da rede de segurança alimentar de Osasco e Carapicuíba. Economia Agrícola, São Paulo, v. 56, p. 7-28, 2009.

PAULILLO, L. F.; PESSANHA, L. Segurança alimentar, políticas públicas e regionalização. In: PAULILLO, L. F. et al. Reestrutração agroindustrial, políticas públicas e segurança alimentar regional. São Carlos: Edufscar, 2002.
SANTANA, J. A. A evolução dos programas de transferência de renda e o Programa Bolsa Família. In: SEMINÁRIO POPULAÇÃO, POBREZA E DESIGUALDADE, 2007, Belo Horizonte, MG. Resumo... Belo Horizonte, MG: Cedeplar/UFMG, 2007. p. 1-19.

SANTOS, S. M. C.;SANTOS, L. M. P. Avaliação de políticas públicas de segurança alimentar e combate à fome no período de 1995-2002 - abordagem metodológica. Cadernos de Saúde Pública, Rio de Janeiro, v. 23, n. 5, p. 1029-1040, 2007.

SEGALL-CORREA, A. M.; MARIN-LEON, L. A segurança alimentar no Brasil: proposição e usos da Escala Brasileira de Medida da Insegurança Alimentar (EBIA) de 2003 a 2009. Segurança Alimentar e Nutricional, Campinas, v. 16, n. 2, p. 1-19, 2009.

SEGALL-CORREA, A. M.; SALLES-COSTA, R. Novas possibilidades de alimentação a caminho? Democracia Viva, n. 39, p. 68-73, jun. 2008.

SILVA NETO, J. M.; MELO, R. P.; PEREIRA, S. A. Resultados notáveis na administração pública: avaliação de programas utilizando mapas estratégicos e o Balanced Scorecard. In: ENCONTRO DA ASSOCIAÇÃO NACIONAL DE PÓS-GRADUAÇÃO E PESQUISA EM ADMINISTRAÇÃO, 30., 2006, Salvador/BA. Resumo... Salvador, BA: EnANPAD, 2006. p. 23-27.

SOUZA, C. Políticas públicas: uma revisão da literatura. Sociologias, Porto Alegre, RS, v. 8, n. 16, p. 20-45, 2006. Disponível em: <http:/ / www.scielo. br/>. Acesso em: 7 dez. 2010. 
